\title{
MÃES CUIDADORAS, PAIS IMPERFEITOS: DIFERENÇAS DE GÉNERO NUMA REVISTA PORTUGUESA PARA MÃES E PAIS ${ }^{1}$
}

\section{Resumo}

A análise de revistas dirigidas a mães permite conhecer os modelos de maternidade dominantes em cada época e a sua evolução e permeabilidade a mudanças sociais, preocupações médicas e estratégias políticas vigentes. Neste artigo, analisamos o conteúdo de 16 artigos da edição portuguesa de 2015 da revista Pais $\mathcal{E}$ Filhos para verificar se ela reflete o maior equilíbrio entre mães e pais no cuidado dos/as filhos/as que é defendido na sociedade atual e promovido na recente legislação sobre licença parental. Os resultados mostram que, apesar de considerar e valorizar o papel do pai na vida da criança, a revista ainda assume que a mãe é a sua principal cuidadora e promove uma parentalidade altamente diferenciada em termos de género.

Palavras-chave: Maternidade, paternidade, diferenças de género, revista, Portugal.

\begin{abstract}
Caring mothers, imperfect fathers: Gender differences in a Portuguese magazine for mothers and fathers

The analysis of magazines targeted to mothers allows us to know current dominant motherhood models, as well as their evolution and permeability to social changes, medical concerns, and existing political strategies. In this article, we analyse the content of 16 articles of the 2015 Portuguese edition of Pais $\mathcal{E}$ Filhos magazine to verify whether it reflects a greater balance between mothers and fathers in the care of children advocated in today's society and promoted on the latest legislation on parental leave. Results show that, despite promoting and valuing the role of the father in children's lives, the magazine still considers that the mother is their main caregiver and promotes highly differentiated parenting in terms of gender.
\end{abstract}

Keywords: Motherhood, fatherhood, gender differences, magazine, Portugal.

Este artigo baseia-se em parte da tese de doutoramento da primeira autora, acessível em $<$ https://hdl.handle.net/10216/120929>, que beneficiou de financiamento da FCT - Fundação para a Ciência e a Tecnologia, através da bolsa SFRH/BD/110262/2015.

* Centro de Psicologia da Universidade do Porto (CPUP), Faculdade de Psicologia e de Ciências da Educação da Universidade do Porto.

Endereço postal: CPUP, Faculdade de Psicologia e de Ciências da Educação da Universidade do Porto, Rua Alfredo Allen, s/n, 4200-135 Porto, Portugal.

Endereço eletrónicos filipa.cesar@gmail.com

ORCID: https: / / orcid.org/0000-0003-2214-9490

** Endereço eletrónico: oliveira@fpce.up.pt

ORCID: http: / / orcid.org/ 0000-0002-8453-1719

*** Endereço eletrónico: fontaine@fpce.up pt

ORCID: https: / / orcid.org/0000-0001-9232-8692 


\begin{abstract}
Résumé
Mères attentionnées, pères imparfaits: différences entre les sexes dans un magazine portugais pour les mères et les pères

Les magazines destinés aux mères nous permettent de connaître les courants modèles de maternité dominants, ainsi que leur perméabilité aux changements sociaux et aux stratégies politiques existant. Dans cet article, nous analysons le contenu de 16 articles de l'édition portugaise de 2015 du magazine Pais $\mathcal{E}$ Filhos afin de voir s'il reflète un plus grand équilibre entre les mères et les pères dans la prise en charge des enfants préconisé par la société d'aujourd'hui et promu par la récente législation portugaise sur le congé parental. Les résultats montrent que, malgré la prise en compte et la valorisation du rôle du père, le magazine suppose toujours que la mère est la principale responsable pour les enfants et encourage une parentalité très différenciée en termes de sexe.
\end{abstract}

Mots-clés: Maternité, paternité, différences entre les sexes, magazines, Portugal.

\title{
Introdução
}

Revistas para mães: evolução e conservadorismo

O exercício da maternidade tem uma forte componente cultural, que depende dos contextos normativos relativos aos papéis sociais de género e que, tradicionalmente, era transmitido pelas próprias mulheres. No século $X X$, revistas dirigidas ao público feminino passaram a informar mulheres e mães sobre como cuidar da sua prole de acordo com os modelos culturais, as preocupações médicas e os objetivos políticos vigentes.

A evolução das sociedades e o seu impacto sobre a definição dos papéis e responsabilidades da mulher também se refletem nas revistas femininas (Demarest e Garner 1992). O declínio progressivo da inclusão de temas como as tarefas domésticas e os cuidados associados à maternidade e o aumento de artigos sobre política, sociedade e economia nestas revistas demonstram que o seu conteúdo acompanha a evolução dos interesses culturais (Demarest e Garner 1992). No entanto, Demarest e Garner (1992) defendem que as revistas populares tendem a ser conservadoras e a promover preferencialmente as normas sociais tradicionais, sendo mais um reflexo de mudanças culturais do que suas promotoras.

Estes meios de comunicação fundamentam-se frequentemente em achados científicos considerados relevantes. As revistas ajudam a divulgar a ciência ao traduzi-la num formato acessível ao seu público e, por seu turno, a ciência é utilizada para legitimar opções políticas e sociais e as revistas tornam-se «guias morais» de quem as lê (Allen 1995). Atualmente, a interação mãe-filho/a é regulada por diversos agentes e especialistas. As mães são instruídas sobre como socializar as crianças a fim de aumentar o seu potencial e são, também, claramente informadas de que o futuro do/a(s) seu/sua(s) filho/a(s) depende diretamente do seu investimento (Smyth 2014). Os média também continuam a exibir estereótipos de género 
particularmente onerosos para as mulheres (Oprea 2016) a respeito de modelos de comportamento, papéis e traços psicológicos que naturalizam uma «maternidade intensiva» (Hays 1996) e exigente, mesmo quando se dirigem aos Pais ${ }^{2}$ e adotam este termo neutro de género (Smyth 2014).

\section{O novo protagonismo do pai}

Milkie e Denny (2014) examinaram os benefícios do envolvimento paterno proposto em revistas para Pais ao longo dos séculos XX e XXI e concluíram que uma «nova paternidade» tem vindo a substituir a divisão tradicional de responsabilidades de género no cuidado dos/as filhos/as. Os benefícios deste envolvimento para os próprios pais, para as crianças e para as mães são cada vez mais reconhecidos. O papel do pai evoluiu das vantagens da interação lúdica com a criança e ganhou um significado mais amplo, inclusivamente de realização pessoal do homem através da paternidade, com ganhos importantes também para a criança (Milkie e Denny 2014).

No entanto, ambientes de trabalho competitivos, exigentes e stressantes para os homens podem afastá-los do ambiente familiar e influenciar a extensão e a natureza do seu envolvimento com os/as filhos/as (LaRossa 2012). A participação dos pais parece depender fortemente de recursos e restrições externas e estruturais, como a pressão no mercado de trabalho, a posição de classe e as políticas da família e do trabalho (Milkie e Denny 2014).

A tímida evolução das políticas públicas, que poderiam ampliar as escolhas dos homens e mudar as suas atitudes, modificando os regimes de horário de trabalho e adaptando as licenças de paternidade, dificulta uma mudança cultural mais profunda (Gregory e Milner 2011). Os governos podem promover uma maior igualdade de género ao implementar políticas de licença parental que ofereçam incentivos e oportunidades tanto à mãe como ao pai, contribuindo assim para mudanças de atitudes e comportamentos de ambos, tanto no trabalho como em casa (Hagqvist et al. 2017). Neste sentido, Farré (2016) propõe períodos de licença exclusivos para os pais como instrumento político destinado a aumentar a sua participação nas tarefas familiares e a facilitar a carreira profissional das mulheres.

As intervenções de profissionais de saúde focadas nas mães e o gatekeeping destas também são barreiras para um maior envolvimento do pai e contribuem para perpetuar as crenças sobre os papéis de género tradicionais na parentalidade (Milkie e Denny 2014; Sicouri et al. 2018). Em assuntos relacionados com a gravidez, o parto e puericultura, os pais devem ser incentivados e capacitados através do acesso a mais informações, de modo a sentirem que podem e devem tomar uma parte ativa nesses processos (Sapountzi-Krepia et al. 2015).

2 Para facilitar a interpretação, neste artigo a palavra «Pais» com maiúscula refere-se a mães e pais. 


\section{Parentalidade em Portugal}

As famílias biparentais portuguesas tendem a ser de dupla carreira (Matias, Andrade e Fontaine 2011) e o mercado de trabalho exige que homens e mulheres tenham qualificações académicas e transversais iguais e dedicação de tempo semelhantes, apesar da persistência de desigualdades de género nos salários e no acesso a posições de liderança (Wall et al. 2016). A este igual envolvimento de homens e mulheres na esfera profissional deveria corresponder um igual envolvimento na esfera familiar.

As políticas públicas portuguesas de licença parental, cuja alteração mais recente ocorreu em 2009, tentam apoiar o envolvimento quer da mãe, quer do pai no cuidado dos/as filhos/as. Já desde 1984, um dos princípios gerais da lei que regula a proteção da maternidade e da paternidade assume que ambos são «valores sociais eminentes» (Assembleia da República 1984, 1149). Em 2009, o Código do Trabalho acrescenta que «os[/as] trabalhadores[/as] têm direito à protecção da sociedade e do Estado no desempenho da sua insubstituível acção em relação ao exercício da parentalidade» (Assembleia da República 2009, 935). Aqui, não só o número de dias de licença parental inicial do pai, nas seis semanas após o nascimento, foi aumentado (em partilha com a mãe), como foi também criada a possibilidade de o pai ficar 30 dias em exclusivo com o bebé após a licença obrigatória da mãe (sem a presença desta), pagos por inteiro (100\%) de modo a criar incentivos à sua utilização. $O$ facto de esta licença não poder ser transferida para a mãe caso não seja utilizada pelo pai parece desafiar a noção de que o cuidado à criança pequena é uma prerrogativa feminina, promove uma maior igualdade de género na conciliação entre a vida profissional e a vida familiar e permite que os pais assumam novas responsabilidades e se liguem mais ao bebé (Wall e Leitão 2017). Este tempo exclusivo do pai permite-lhe assumir um papel cuidador, contribuindo para uma maior igualdade de género na parentalidade e tem, portanto, uma intenção de mudança social em linha com o conceito de «masculinidade cuidadora» introduzido por Elliott (2016).

A análise comparativa de vários países relativamente às licenças de parentalidade e de paternidade exclusiva (Wall e O'Brien 2017) revelam que a mudança social não depende só da lei, mas também dos modelos culturais familiares e de género e do mercado de trabalho, mais ou menos permeáveis a mudanças que, regra geral, se revelam lentas. Efetivamente, nos países onde a licença parental exclusiva do pai existe há mais tempo, o seu usufruto é considerado um dado adquirido pelos pais e não é socialmente questionado. Nos países onde essa licença é mais recente, os pais enfrentam o desconforto de ter que se valer do direito que lhes é atribuído por lei. Em Portugal, a implementação desse direito exige dos pais assertividade e negociação, tanto na esfera privada, como no domínio público, nomeadamente no local de trabalho (Mello e Tan 2016). Ou seja, mesmo quando o maior envolvimento do pai na vida da criança é considerado benéfico, a secunda- 
rização do papel profissional pelo pai não é necessariamente bem tolerada. Diversas barreiras sociais e culturais opõem-se à implementação desta nova forma de masculinidade, e isto permite que, em Portugal, coexistam múltiplas e diferentes apropriações do papel de pai e experiências de paternidade (Wall e Leitão 2017). Os pais podem assumir diferentes formas de relação com os/as filhos/as e de coparentalidade, com efeitos ao nível da sua própria identidade nesse papel e no tipo de práticas que implementam (Marinho 2011).

\section{Objetivos e questões de investigação}

Além dos média online (César, Oliveira e Fontaine 2018), a imprensa escrita, nomeadamente as revistas sobre parentalidade, continua a influenciar tanto mães como pais. Neste artigo, analisamos o conteúdo de uma revista portuguesa destinada a ambos - a Pais E Filhos (P\&F) - com o objetivo de verificar se ela promove este novo modelo de parentalidade que visa uma divisão mais igualitária da criação dos/as filhos/as, refletindo a intenção da legislação portuguesa, ou se, pelo contrário, reflete os papéis de género tradicionais e diferenciados na família.

A nossa primeira questão de investigação é se, apesar do título neutro (Pais), a revista se dirige principalmente às mães, reproduzindo e reforçando o modelo que as considera as principais responsáveis por criar os/as filhos/as e, portanto, o principal público de uma publicação deste âmbito (q1). A nossa segunda questão de investigação pretende determinar se, quando mães e pais são abordados/as, retratados/as e/ou interpelados/as separadamente na revista, os estereótipos de género são reforçados. Será o caso se permanecerem no discurso dos artigos as diferenças de género que refletem os papéis tradicionais na família (Parsons 2002) e que atribuem à mãe e ao pai responsabilidades diferentes no que toca ao cuidado dos/as filhos/as e ao envolvimento noutros papéis sociais, como o profissional (q2).

\section{Método}

Segundo os dados obtidos no site da Associação Portuguesa para o Controlo de Tiragem e Circulação (APCT) ${ }^{3}$, entre as revistas dirigidas a mães e/ou pais disponíveis em 2015, período temporal a que corresponde a recolha de dados em que este estudo se integra, a P\&F foi a publicação mais frequente ao longo do ano (periodicidade mensal), e também a que se dirige ao período mais longo de parentalidade (da gravidez da mãe à adolescência da criança). Foi também a revista com a maior tiragem nesse ano (10 500 cópias).

\footnotetext{
$3 \quad<$ http://www.apct.pt/Analise_simples.php $>$.
} 
A política editorial da P\&F consistia em publicar informações úteis e científicas para mães e pais, com contribuições de psicólogos/as, pediatras e outros/as especialistas («porque a intuição não é suficiente», de acordo com o subtítulo), e de jornalistas e celebridades que também são mães ou pais. A amostra para proceder à análise do seu conteúdo integrou o conjunto de artigos dedicados ao tema de capa de cada uma das 12 edições de 2015 (num total de 16 artigos, por haver mais do que um artigo em algumas das edições - cf. Tabela 1) no pressuposto de que estes refletiriam melhor a política editorial da revista.

Tabela 1.

Temas de capa da revista P\&F em 2015 e títulos dos artigos

\begin{tabular}{|c|c|c|c|}
\hline Mês & Tema de capa & Artigos & Páginas \\
\hline Janeiro & $\begin{array}{l}\text { Em } 2015 \text { vamos... } 12 \text { promessas para } \\
\text { um ano mais feliz }\end{array}$ & Em 2015 vou... & $71-73$ \\
\hline Fevereiro & $\begin{array}{l}\text { Que nome lhe dou? A escolha, o } \\
\text { significado, as modas e as proibições }\end{array}$ & Em nome... do nome & $39-41$ \\
\hline \multirow{2}{*}{ Março } & \multirow{2}{*}{$\begin{array}{l}\text { Sou um bom pai? Como os filhos nos } \\
\text { mudam o sentido da vida }\end{array}$} & Que pai quero ser? & $67-69$ \\
\hline & & Ser pai muda tudo & $70-76$ \\
\hline Abril & $\begin{array}{l}\text { Já não gosto de ti! O que as crianças } \\
\text { aprendem quando se zangam }\end{array}$ & Já não sou tua amiga! & $36-39$ \\
\hline \multirow{2}{*}{ Maio } & \multirow{2}{*}{ Mães de corpo e alma } & Mães com garra & $16-20$ \\
\hline & & Ser mãe é... & $26-27$ \\
\hline Junho & Crianças. O futuro é delas & O mundo é deles! & $18-24$ \\
\hline Julho & Férias diferentes & Férias diferentes & $14-20$ \\
\hline Agosto & $\begin{array}{l}\text { Hora de parar. As crianças também } \\
\text { podem meditar }\end{array}$ & Aqui e agora & $14-19$ \\
\hline \multirow{3}{*}{ Setembro } & \multirow{3}{*}{$\begin{array}{l}\text { Escola. Tudo para entrar com o pé } \\
\text { direito }\end{array}$} & Estreia na creche & $26-29$ \\
\hline & & $\begin{array}{l}\text { Regresso às aulas sem } \\
\text { pressões }\end{array}$ & $32-35$ \\
\hline & & O novo janeiro & $44-47$ \\
\hline Outubro & $\begin{array}{l}\text { Por que é que as crianças precisam } \\
\text { tanto delas }\end{array}$ & A importância dos limites & $18-23$ \\
\hline Novembro & Filhos. Temos mesmo um preferido? & Ode ao filho «mais que tudo» & $14-19$ \\
\hline Dezembro & Natal. Ajude-os a acreditar na magia & Sim, o Pai Natal existe! & $32-37$ \\
\hline
\end{tabular}

Todo o conteúdo de cada artigo referente aos temas de capa foi analisado de acordo com as questões da pesquisa. Anúncios e imagens não foram considerados. As 16 unidades de texto foram digitalizadas e carregadas no programa NVivo12, com recurso ao qual os textos foram analisados por dois/duas pesquisadores/as, alcançando um total de concordância de $92 \%$. 
O tempo e os recursos disponíveis não permitiram a análise de todo o conteúdo das 12 edições de 2015 da revista P\&F, portanto a principal limitação deste estudo reside no facto de terem sido analisados apenas os temas de capa. A autoria dos artigos também não foi considerada, e por isso não é mencionada, por não ser tão relevante quanto a forma como os/as redatores/as expressam os objetivos e a linha editorial da revista.

\section{Resultados}

A análise de conteúdo mostrou que a maioria dos temas de capa em 2015 se dirigia quer a mães, quer a pais, não os diferenciando. Os artigos focam assuntos genéricos e permitem responder negativamente à nossa primeira questão de investigação (q1): a revista P\&F não é sobretudo dirigida a mães e parece assumir a responsabilidade partilhada dos Pais na educação das crianças.

No entanto, constata-se que alguns dos artigos são dirigidos ao público feminino, o que permite responder de forma afirmativa a esta mesma questão (q1). Na edição de janeiro, apesar de título e subtítulo serem neutros em termos de género («Em 2015 vou...»), a análise do artigo revela que as 12 sugestões de «promessas para um ano mais feliz» são dirigidas às mães, como, por exemplo, a sugestão número sete, «Desistir de tentar ser perfeita»:

Felizmente há cada vez mais mães que não querem ser perfeitas [...]. Mães que nem sempre têm a casa impecável, que às vezes fazem massa com atum para o jantar, que não dão banho aos filhos todos os dias, que têm vida própria... (janeiro, 72)

A sugestão número oito, «Dedicar-me mais ao que gosto», também especifica que «não precisa de colocar os filhos em segundo lugar, mas talvez tenha de dar menos importância a outras coisas, como ter a casa sempre impecável» (janeiro, 73).

Estes conselhos pressupõem que as mães podem ter um quotidiano mais relaxado se se preocuparem menos com as tarefas domésticas, os banhos dos/as filhos/as e cozinhar, responsabilidades que lhes estão atribuídas nas famílias com papéis de género tradicionais. A partilha destas responsabilidades, nomeadamente com o pai, nunca é sugerida, e assim o artigo reforça uma clara diferenciação de papéis de género na família.

O mesmo acontece na edição de setembro, que se refere ao início do ano escolar, um momento de apreensão e ansiedade para os Pais e «um momento importante para toda a família» (setembro, 28). No entanto, o artigo só contém testemunhos de sentimentos de mães: dúvida, preocupação e medo. Os sentimentos de pais ou não foram ouvidos, ou não foram considerados dignos de registo.

Em duas edições específicas, março (dia do pai) e maio (dia da mãe), cada um dos Pais é tema de capa e de dois tipos de artigos: um primeiro tipo apresenta testemunhos de mães e de pais escolhidos pela P\&F para contar a sua história e experiências pessoais; o outro tipo apresenta reflexões de especialistas (psicólogas) 
sobre o que significa (ou deveria significar) ser mãe e ser pai no contexto atual. Estes dois tipos de artigos foram analisados detalhadamente e comparados no sentido de verificar as principais diferenças e semelhanças na forma como pais e mães são retratados/as e interpelados/as, a fim de responder à nossa segunda questão de investigação (q2) acerca da manutenção ou evolução dos papéis tradicionais na maternidade e na paternidade.

\section{Histórias pessoais de mães e de pais}

A edição de maio descreve as histórias de vida de cinco mulheres anónimas (M1, M2, M3, M4, M5) a quem a maternidade «traçou o destino», transformando-as em «pessoas melhores» (maio, 16). Algumas delas têm em comum a prioridade relativa que as mães atribuem ao seu papel profissional ou à sua vida pessoal: a M1 deixou o emprego quando o seu primeiro filho nasceu e, desde então, tem vindo a desenvolver projetos sucessivos de cariz mais emocional do que lucrativo, «e tudo isto sempre com os meus filhos atrás de mim!» (M1, maio, 18). Também a M5 tem um horário de trabalho flexível e o seu filho mais novo acompanha-a sempre. Já a M2 colocou a sua saúde em risco quando decidiu ter uma segunda gravidez depois de um cancro da mama; as pessoas disseram que ela era «doida», mas ela explica que os filhos «são tudo» para ela (M2, maio, 19). Todas as mães revelam orgulho na forma como gerem todas as suas tarefas e ultrapassam dificuldades em nome dos/as seus/suas filhos/as: a M5 prioriza-os/as relativamente à «casa desarrumada ou [a]o jantar for fazer» (M5, maio, 22); a M4 explica que «eles precisavam de mim e que, por eles, tinha de estar bem, feliz e equilibrada» (M4, maio, 24); a M2 afirma que nunca esteve deprimida, nem mesmo quando estava doente (maio, 19).

Apenas a M3, mãe de quatro, é apresentada como sendo advogada, voluntária numa instituição e com funções nas autoridades locais. Ela admite que não é fácil gerir todas as suas atividades, mas tanto ela como a M5, que é mãe de seis, afirmam que a organização é a chave para gerir os seus quotidianos. A M5 delega tarefas e responsabilidades nos/as filhos/as e afirma ter o apoio de uma boa rede familiar e um «super-marido» (M5, maio, 22).

De igual modo, o artigo do dia do pai apresenta o testemunho de cinco pais (P1, P2, P3, P4, P5) que são figuras públicas em Portugal. Apresenta-os como homens «brilhantes nas suas carreiras, [que] marcam pela forma apaixonada como abraçam o talento que lhes é inato e além disto tudo também são... PAIS!» (março, 70). A diferença na apresentação destes casos exemplares de mães e pais vai ao encontro da nossa segunda questão de investigação (q2): as atividades profissionais dos pais são valorizadas e publicamente reconhecidas, e as das mães são secundarizadas. Duas mães da edição de maio tinham posto de parte as suas carreiras (M1, M5) e outras duas nem sequer a mencionaram (M2, M4). 
O título, «ser pai muda tudo», induz o/a leitor/a a acreditar que as vidas destes homens mudaram radicalmente com o nascimento dos/as filhos/as. No entanto, todos eles confirmam que a grande mudança foi interior e emocional: um amor novo e forte por outra pessoa e uma enorme responsabilidade acrescida. O P1 considera que «a real reviravolta é interior e inconsciente» e que a «mudança mais marcante» foi «aquela nova forma de amor por outro ser humano» (P1, março, 71-72). O P2, mais velho e com filhos/as já adultos/as, diz que enfrentou «o maior desafio que tinha vivido até então», que as mudanças foram «um crescimento pessoal» e refere o sentimento de uma responsabilidade muito maior (P2, março, 72). Com quatro filhos/as entre os 12 e os 22 anos, o P3 refere «a consciencialização da necessidade de estarmos presentes, de termos de viver, de desejarmos profundamente estar lá, no caminho, com aquela pessoa», uma mudança que «se vai tornando cada vez mais presente [...] e vamos aprendendo» (P3, março, 74).

As mudanças de vida concretas aconteceram apenas aos pais mais jovens. $\mathrm{O}$ P5, que tem duas filhas de 10 e 2 anos, concorda que «há uma vida antes dos filhos e outra depois de eles nascerem» (P5, março, 76), não apenas emocionalmente, mas também em termos de horários e de organização que, no fundo, dependem deles. O P1, cujo filho tem 5 anos, refere mudanças de rotina e noites sem dormir que, para sua surpresa, não interferiram com o seu trabalho. Com uma filha de um ano, o P4 diz que a paternidade o fez «pensar muito mais na família e deixamos de ser tão egoístas. Ganhamos responsabilidade, mas com gosto; fazemos sacrifícios se tivermos de fazê-los, mas felizes, quase sem notarmos porque é algo que nos sai naturalmente» ( $\mathrm{P} 4$, março, 75). A maior mudança foi operada pelo P4, um ex-desportista de alta competição que jogava num clube estrangeiro e que não só regressou a Portugal, como também mudou de profissão, relegando o desporto para terceiro lugar, a seguir à família e ao trabalho.

Quanto às diferenças relativamente à maternidade, estes homens referem--se à gravidez como um período em que só as mães têm real noção do/a bebé e conseguem estabelecer uma relação emocional com ele/a, o que os deixa numa posição de desvantagem. Só depois do nascimento é que eles conseguem sentir a paternidade de uma forma plena. No entanto, o P3 considera que é mais difícil ser alguém que deixa uma marca na vida da criança do que ser um mero cuidador. $O$ pai mais velho (P2) assume que teve um papel diferente, mas complementar ao da mãe, e que só após o divórcio, confessa, quando periodicamente tinha a guarda dos/as filhos/as e era o seu único cuidador, sentiu por vezes uma angústia parecida com a de uma «quase-mãe» (P2, março, 73). O P1 argumenta que a adaptação a este novo papel foi «natural», embora ele continue a «tentar [...] com graus variáveis de sucesso», ser menos «aluado» e mais atento (P1, março, 72), uma afirmação que, possivelmente, não seria admissível a uma mãe. Além disso, o P4 diz «gosto mesmo de ajudar e fazer tudo o que está ao meu alcance, não consigo imaginar as coisas de modo diferente» (P4, março, 75). As expressões «ajudar» e «ao alcance» atribuem o cuidado principal à mãe e um papel suplementar ao pai, o que revela 
a assunção de diferenças de género tradicionais nos papéis parentais. Só o P5 se assume como um pai muito presente na vida das filhas e faz questão de partilhar completamente o cuidado destas com a mãe. Os pais também expressam alguns sentimentos negativos relativamente à paternidade, nomeadamente comoção, sensibilidade, preocupação e medo, mas todos concordam que estas adversidades os tornaram pessoas melhores e mais fortes.

Por fim, o P3 lamenta a falta de informação específica para pais e futuros pais, já que toda ela é dirigida a mães. Na sua opinião, esta «lacuna imensa» explica o não envolvimento dos pais neste processo: «a sociedade melhoraria incomensuravelmente se esta responsabilização do pai fosse promovida como é perante a mãe» (P3, março, 74).

\section{$A$ «boa» mãe e o «bom» pai}

O outro tipo de artigos, escrito por psicólogas, centra-se no significado normativo da maternidade e da paternidade. O título da edição de maio (p. 26) é «Ser mãe é...» e inclui várias formas de completar esta frase e de dar resposta ao que é ser mãe, enquanto a edição de março (p. 67) questiona «Que tipo de pai quero ser?» e desafia os pais a verificarem «a relação que têm com os filhos e a forma como estão a ser pais».

Em maio (p. 26), a revista explica que «não há desafio de vida mais completo, mais empolgante, mais exigente, mais permanente» do que ser mãe. Afirma que todas as mães são supermães, apesar de todas terem dúvidas e falhas, e para que se «responsabilize pelo saudável crescimento de um ser humano [...] os únicos dois ingredientes de sucesso garantido são: a presença e o amor incondicional» (p. 26). Acrescenta que ser mãe significa, para uma mulher, «multiplicar-se», «transcender-se», «tornar-se imortal na memória dos nossos filhos», «aproveitar desde o início», «ser lugar de MUITO colo e MUITO mimo», «ser atenta ao que faz dos seus filhos únicos e especiais», e «ser mãe para sempre» (p. 26-27). Além disso, afirma que a maternidade se torna omnipresente nos pensamentos e ações das mulheres mesmo antes da gravidez, uma época que deve ser vivida intensamente, e que está na origem de fortes emoções, quer positivas, quer negativas. Entre estas, predominam as dúvidas e a incerteza, e as mães navegam à vista, reinventando recursos.

A perpetuidade das ações das mães é evocada através dos «valores de que falamos e de que somos exemplo [...] que atravessarão gerações, porque, ao educar os nossos filhos, estamos também a educar os Pais em que se vão tornar» (maio, 26). As mães também são criticadas: «muitas vezes gostávamos de superar nos nossos filhos as nossas escolhas erradas e de projetar neles as nossas paixões [...] e por vezes confundimos o «melhor» com «o melhor à nossa moda»», seguido da explicação de que «é fundamental ver os filhos com realismo, como verdadeira- 
mente são, e dar-lhes o espaço e o apoio para irem desenvolvendo as suas próprias competências e características» (p. 27).

No artigo dos pais, cada um dos 12 itens de verificação apresentados é baseado em estudos psicológicos que provaram que «o envolvimento e a presença paterna é determinante no desenvolvimento de competências dos filhos e que o pai é essencial e insubstituível no desenvolvimento das crianças e adolescentes» (março, 67). A revista assegura que «durante demasiado tempo o papel do pai foi desconsiderado (e os filhos é que perdiam com isso!)» (p. 67). Parece ser tempo de atribuir aos pais o papel que as crianças merecem que eles tenham, «um papel especial enquanto companheiro privilegiado da brincadeira, da aventura, o que apela à imaginação e desafia novas conquistas!» (p. 67). Além disso,

precisam-se de pais verdadeiramente envolvidos nas várias dimensões da vida dos filhos: pais que brincam, pais que estudam, pais que riem, pais que ralham, pais que perguntam, pais que ouvem, pais que protegem, pais que ajudam, pais que abraçam, pais que encorajam, pais que seguram, pais que orientam... (p. 67)

Por outro lado, este é um artigo muito crítico, baseado na ideia estereotipada de que um pai não parece saber como interagir adequadamente com as crianças. Os pais são aconselhados a corrigir alguns erros supostamente comuns e, portanto, podemos assumir que precisam de ser ensinados e alertados de uma forma mais básica e clara do que as mães. O primeiro item urge os pais a serem melhores pais, mas também a aceitar que nunca vão ser pais perfeitos: «este idealismo inibe muitas vezes a ação» e acaba por ser prejudicial (março, 67). O segundo item também se baseia no pressuposto de que, apesar de os pais serem emocionalmente próximos dos/as filhos/as, «é engraçado ver que» (p. 68) não o mostram suficientemente porque o trabalho tem prioridade. Para que consigam ajustar o seu comportamento a esta importância emocional, os pais têm de mostrar que estão interessados na vida dos/as filhos/as, fazendo-lhes perguntas: «tente perceber o que se passa com os amigos, e na escola, que alegrias e aborrecimentos teve...» (p. 68). Ao contrário do que acontece quando a P\&F se dirige às mães, as tarefas de cuidado não são mencionadas.

Os outros erros que a P\&F atribui aos pais, na linha de crítica/correção que parece ser a sua marca, incluem não proporcionar às crianças tempo suficiente para fazerem as coisas ao seu ritmo, falar sobre a escola focando apenas as notas e os trabalhos de casa, comparar o/a filho/a a outros/as, ser demasiado exigente com o seu comportamento, não o/a felicitar o suficiente pelas suas conquistas ou, inversamente, aplaudi-lo/a de forma irrealista, não usar técnicas de comunicação adequadas (usando questões fechadas, forçando a criança a falar quando não lhe apetece, usando o sarcasmo e a humilhação, fazendo promessas que não consegue cumprir), sendo intrusivo nas tomadas de decisão das crianças, e não parar para pensar sobre que valores estão a transmitir aos/às filhos/as. Para cada erro, 
explicam-se as respetivas consequências danosas para a criança e a forma correta de agir. $\mathrm{O}$ artigo termina apelando à criatividade dos pais «para fazer desdobrar o tempo, para interromper uma birra, para brincar, para resolver problemas» (março, 69).

\section{Discussão e conclusões}

Neste artigo tentámos verificar se a revista P\&F tenta promover uma divisão do cuidado com as crianças mais igualitária e atenuar as diferenças de género nos papéis familiares de mães e pais, aliás refletida na legislação portuguesa mais recente sobre licença parental. Esta considera que os pais são capazes de tomar conta de uma criança sozinhos e atribuir-lhes um tempo de licença exclusivo para ficar com os/as filhos/as após o nascimento.

A análise das 12 edições de 2015 da revista P\&F revela que a sua linha editorial tende a dirigir-se aos Pais, incluindo, portanto, o pai no seu público-alvo. Isto pode ser considerado um sinal positivo de mudança: ajudar a escolher o nome do bebé, sugerir atividades e férias em conjunto, aprender a lidar com situações difíceis para a criança e a prepará-la para o futuro são temas já não apenas transmitidos às mães (Proctor e Weaver 2017). Isto indica uma evolução na partilha das responsabilidades parentais, sobretudo no que diz respeito à educação da criança. No entanto, a divisão de papéis de género na parentalidade é clara e a revista assume que as tarefas de cuidado dos/as filhos/as são, claramente, responsabilidade da mãe, enquanto o pai tem um papel mais educativo e lúdico.

Os artigos que são dirigidos a mães e a pais separadamente assumem que a mãe é a principal cuidadora no quotidiano e, portanto, transmitem inequivocamente as diferenças de género tradicionais nos papéis familiares (Oprea 2016). Enquanto a revista atribui maior importância à carreira profissional dos pais relativamente à das mães, as tarefas como alimentar os/as filhos/as, dar-lhes banho e levá-los/as à escola são apenas atribuídas às mães, nomeadamente nas edições de março e maio. É possível que a prioridade da P\&F seja que os/as seus/suas leitores/as se identifiquem com o que leem e se reconheçam nesta divisão tradicional de responsabilidades e tarefas familiares. No entanto, podemos constatar, em linha com Demarest e Garner (1992), que, como outras, esta revista é conservadora e contribui para a manutenção de normas sociais tradicionais, mais do que para a promoção de mudanças. $\mathrm{O}$ facto de os artigos que apresentam maior diferenciação de género serem escritos por psicólogos/as e se basearem em estudos científicos tem como função legitimar esta mesma diferenciação (Allen 1995).

Não obstante, é evidente que a P\&F tenta valorizar o papel do pai. Não só a importância dos pais na vida dos/as filhos/as é enfatizada na edição de março, o inverso acontece com o impacto positivo que eles/as têm na vida dos pais, sobretudo do ponto de vista emocional. Todos os pais entrevistados admitem que a 
paternidade lhes proporcionou uma mudança interior considerável, mas apenas os mais novos e/ou mais recentes referem mudanças de atitudes e de rotinas, desde o apoio às mães até à partilha total do cuidado, o que pode indiciar uma evolução geracional neste papel, pelo menos nesta amostra. $\mathrm{O}$ recurso a pais que são celebridades em Portugal pode oferecer aos pais leitores modelos de identificação, sendo alguém a quem eles reconhecem, também, valor profissional.

Noutra perspetiva, a apresentação de várias formas de viver a paternidade (cinco, no caso do artigo de março) e a sua valorização indiferenciada legitimam as situações de partilha não equitativa da responsabilidade parental com a mãe. Estes cinco casos evidenciam as várias opções que os pais podem fazer enquanto tal e acaba por não promover especificamente uma «nova paternidade» (Gregory e Milner 2011) mais igualitária. Neste sentido, a P\&F reflete - e legitima - a pluralização de opções e de caminhos que a nova legislação permite, de acordo com Wall e Leitão (2017) e de que os pais se apropriam na diversidade das possibilidades de exercício deste papel (Marinho 2011). Além disso, os pais são amplamente criticados nas suas supostas ações erradas, para depois serem ensinados a compreender e a relacionar-se adequadamente com os/as seus/suas filhos/as. O objetivo parece ser ensinar os pais a educá-los/as, especialmente durante a idade escolar, e a estreitar os seus laços, sendo companheiros. Esta estratégia pode indicar que a maternidade já tem uma forma de manifestação bem definida, enquanto a paternidade está em evolução e, por isso, os pais precisam de maior orientação e formação. Mas o seu papel de eventuais cuidadores nunca é abordado.

As diferenças no criticismo e aconselhamento a mães e a pais são bastante evidentes: as mães devem desistir de tentar ser perfeitas (cf. janeiro), os pais devem ter consciência de que nunca o serão (cf. março). As recomendações dirigidas às mães poderiam ser dirigidas a ambos. Mas, para as mães, o suposto ideal de perfeição refere-se à alimentação e higiene das crianças e a tarefas domésticas de limpeza, o que reproduz estereótipos de género familiares (Oprea 2016). Por seu turno, quando a revista se dirige aos pais e refere práticas de cuidado, incentiva-os a promover a autonomia dos/as filhos/as e a deixá-los/as aprender ao seu próprio ritmo.

Assim, podemos concluir que, contrariamente à intenção da legislação mais recente, a revista $P \& F$ reflete um modelo cultural tradicional de diferenciação de papéis de género na família, ao invés de promover mudanças culturais (Gregory e Milner 2011). Nem na edição de setembro, que aborda a ida dos bebés para a creche, refere a licença parental vigente, que promove a participação dos pais nos seus primeiros meses de vida. As dificuldades inerentes à pressão do mercado de trabalho e a responsabilidade social de facilitar aos homens a experiência da paternidade também não são abordadas (Mello e Tan 2016).

A dualidade de critérios é clara. A P\&F sublinha em março a importância dos pais na transmissão de valores e a partilha de experiências divertidas, corrige-os nas suas imperfeições e legitima diferentes formas de assumir a paternidade. 
Em maio, elogia mães que secundarizam a sua saúde e a sua carreira em favor da maternidade e as exigências deste papel: o de principal e insubstituível cuidadora. A revista reflete e reforça uma clara diferenciação de género nos papéis parentais, legitimando pela mão de especialistas (nomeadamente psicólogos/as) situações de desigualdade que se afastam dos ideais de parentalidade partilhada que, como vimos, beneficiam todos os agentes familiares envolvidos e são, cada vez mais, um objetivo de mudança social.

\section{Referências bibliográficas}

Allen, Katherine R. 1995. «Mothers and work in popular American magazines» by Kathryn Keller; «Representations of Motherhood» by Donna Bassin, Margaret Honey, Meryle Mahrer Kaplan.» Journal of Marriage and Family 57 (4): 1123-1124. DOI: https://doi. org $/ 10.2307 / 353429$

Assembleia da República. 1984. «Lei n. ${ }^{\circ}$ 4/84.» Diário da República 1. ${ }^{a}$ série, 81: 1149-1153. Disponível em https://dre.pt/application/file/88953

Assembleia da República. 2009. «Lei n. 7 /2009.» Diário da República 1. a série 30: 926-1029. Disponível em https://dre.pt/application/file/129757

César, Filipa, Alexandra Oliveira, e Anne Marie Fontaine. 20 18. «O papel do Facebook na difusão de modelos sociais de maternidade em Portugal.» Análise Psicológica 36 (1): 47-59. DOI: https://doi.org/10.14417/ap.1333

Demarest, Jack, e Jeanette Garner. 1992. «The representation of women's roles in women's magazines over the past 30 years.» The Journal of Psychology 126 (4): 357-368. DOI: https://doi.org/10.1080/00223980.1992.10543369

Elliott, Karla. 2016. «Caring Masculinities: Theorizing an emerging concept.» Men and Masculinities 19 (3): 240-259. DOI: https://doi.org/10.1177/1097184X15576203

Farré, Lídia. 2016. «Parental leave policies and gender equality: A survey of the literature.» Estudios de Economia Aplicada 34 (1): 45-60. Disponível em http://ojs.ual.es/ojs/index. $\mathrm{php} / \mathrm{eea} /$ article/view/3005

Gregory, Abigail, e Susan Milner. 2011. «What is 'new' about fatherhood?: The social construction of fatherhood in France and the UK.» Men and Masculinities 14 (5): 588-606. DOI: https://doi.org/10.1177/1097184X11412940

Hagqvist, Emma, Mikael Nordenmark, Glòria Pérez, Sara T. Aleman, e Katja G. Gådin. 2017. «Parental leave policies and time use for mothers and fathers: A case study of Spain and Sweden.» Society Health E Vulnerability 8 (1): 2-12. DOI: https://doi.org/10. 1080/20021518.2017.1374103

Hays, Sharon. 1996. The cultural contradictions of motherhood. New Haven, CT/London: Yale University Press.

LaRossa, Ralph. 2012. «The historical study of fatherhood: Theoretical and methodological considerations.» In Fatherhood in late modernity: Cultural images, social practices, structural frames, organizado por Mechtild Oechsle, Ursula Müller e Sabine Hess, 37-50. Leverkusen: Barbara Budrich. DOI: https://doi.org/10.2307/j.ctvddzvgg.4

Marinho, Sofia. 2011. «Paternidades de Hoje: Significados, Práticas e Negociações da Parentalidade na Conjugalidade e na Residência Alternada.» Tese de doutoramento, Universidade de Lisboa, Instituto de Ciências Sociais. 
Matias, Marisa, Cláudia Andrade, e Anne Marie Fontaine. 2011. «Diferenças de género no conflito trabalho-família: Um estudo com famílias portuguesas de duplo-emprego com filhos em idade pré-escolar.» Psicologia 25 (1): 9-32. DOI: https://doi.org/10.17575/ rpsicol.v25i1.277

Mello, Susan, e Andy S. L. Tan. 2016. «Who's responsible? Media framing of pediatric environmental health and mothers' perceptions of accountability.» Journal of Health Communication 21 (12): 1217-1226. DOI: https://doi.org/10.1080/10810730.2016.1240267

Milkie, Melissa A., e Kathleen E. Denny. 2014. "Changes in the cultural model of father involvement: Descriptions of benefits to fathers, children, and mothers in parents magazine, 1926-2006.» Journal of Family Issues 35 (2): 223-253. DOI: https://doi. org $/ 10.1177 / 0192513 \times 12462566$

Oprea, Denisa-Adriana. 2016. «Between the heroine mother and the absent woman: Motherhood and womanhood in the communist magazine Femeia.» European Journal of Women's Studies 23 (3): 281-296. DOI: https://doi.org/10.1177/1350506815585177

Parsons, Talcott (2002). Family socialization and interaction process. London: Routledge \& Kegan Paul.

Proctor, Helen, e Heather Weaver. 2017. «Creating an educational home: Mothering for schooling in the Australian Women's Weekly, 1943-1960.» Paedagogica Historica 53 (1-2): 49-70. DOI: https://doi.org/10.1080/00309230.2016.1240209

Sapountzi-Krepia, Despina, Maria Psychogiou, Evanthia Sakellari, Maria Tsiligiri, e Katri Vehvilainen-Julkunen. 2015. "Greek fathers' experiences from their wife's/partner's labour and delivery: A qualitative approach.» International Journal of Nursing Practice 21 (5): 470-477. Disponível em https://onlinelibrary.wiley.com/doi/10.1111/ijn.12326

Sicouri, Gemma, Lucy Tully, Daniel Collins, Matthew Burn, Kristina Sargeant, Paul Frick, Vicki Anderson et al. 2018. «Toward father-friendly parenting interventions: A qualitative study.» Australian and New Zealand Journal of Family Therapy 39 (2): 218-231. Disponível em https://www.ncbi.nlm.nih.gov/pmc/articles/PMC6033039

Smyth, Ciara. 2014. «Boost your preschooler's brain power! An analysis of advice to parents from an Australian government-funded website.» Women's Studies International Forum 45: 10-18. DOI: https://doi.org/10.1016/j.wsif.2014.03.011

Wall, Karin, Vanessa Cunha, Susana Atalaia, Leonor Rodrigues, Rita Correia, Sónia Vladimira Correia, e Rodrigo Rosa. 2016. Livro branco. Homens e igualdade de género em Portugal. Lisboa: Instituto de Ciências Sociais/Comissão para a Igualdade no Trabalho e no Emprego. Disponível em http://cite.gov.pt/asstscite/images/papelhomens/ Livro_Branco_Homens_Igualdade_G.pdf

Wall, Karin, e Mafalda Leitão. 2017. «Fathers on leave alone in Portugal: Lived experiences and impact of forerunner fathers.» In Comparative perspectives on work-life balance and gender equality. Fathers on leave alone, editado por Margaret O'Brien e Karin Wall, 45-67. Cham, Suíça: Springer Open. DOI: https://doi.org/10.1007/978-3-319-42970-0_4

Wall, Karin, e Margaret O’Brien. 2017. «Discussion and Conclusions.»In Comparative perspectives on work-life balance and gender equality. Fathers on leave alone, editado por Margaret O’Brien e Karin Wall, 257-266. Cham, Suíça: Springer Open. DOI: https://doi. org/10.1007/978-3-319-42970-0_14

Filipa César. Licenciada em Sociologia, mestre em Ciências da Educação e doutora em Psicologia pela Faculdade de Psicologia e de Ciências da Educação da Universidade do Porto. A sua tese de doutoramento versou sobre modelos de maternidade e 
suas implicações nas motivações, expectativas e realidades das mães portuguesas, tema de investigação a que se dedica atualmente e a propósito do qual tem publicado em revistas nacionais e internacionais e participado em eventos públicos e académicos.

Endereço eletrónico: filipa.cesar@gmail.com

Alexandra Oliveira. Professora e investigadora da Universidade do Porto - Faculdade de Psicologia e Ciências da Educação. Os seus interesses de pesquisa estão relacionados com género, sexualidade e não normatividade, com foco principal no trabalho sexual. Concluiu o doutoramento em Psicologia na Universidade do Porto com uma pesquisa etnográfica sobre trabalho de sexo na rua. Tem conduzido várias investigações sobre a indústria do sexo e publicou três livros (um deles em coautoria), vários artigos e capítulos de livros.

Endereço eletrónico: oliveira@fpce.up.pt

Anne Marie Fontaine. Professora Emérita da Faculdade de Psicologia e de Ciências da Educação da Universidade do Porto. Os seus interesses de investigação incluem motivação e resiliência, influências do contexto social no desenvolvimento diferencial da adolescência a idade adulta, influências culturais e sociais - nomeadamente dos papéis de género - em projetos de vida, equilíbrio trabalho/família, parentalidade e novas configurações familiares, solidariedade intergeracional. Tem mais de 160 publicações, é investigadora responsável de vários projetos financiados.

Endereço eletrónico: fontaine@fpce.up.pt

Artigo recebido a 15 de fevereiro de 2020 e aceite para publicação a 6 de abril de 2020 